\title{
ANALISIS ALOKASI BIAYA BERSAMA UNTUK PENENTUAN BIAYA PRODUKSI NUTELLA CHEESE CUPCAKE DAN COOKIES CUPCAKE PADA SHMILY CUPCAKES SAMRAT MANADO
}

\author{
Olivia A. Tumbol \\ Jantje Tinangon \\ Stanley Kho Walandow \\ Fakultas Ekonomi Jurusan Akuntansi \\ Universitas Sam Ratulangi Manado \\ email: olivia_tumbol@yahoo.com
}

\begin{abstract}
ABSTRAK
Dalam meningkatkan usahanya perusahaan perlu melakukan proses produksi yang tepat supaya produk yang dihasilkan mampu bersaing di pasaran. Salah satu usaha tersebut yaitu dengan memanfaatkan satu atau beberapa bahan baku utama untuk menghasilkan dua atau lebih jenis produk yang hampir sama tetapi dengan variasi yang berbeda dengan mengalokasikan biayanya secara akurat pada masing-masing produk sehingga dapat memaksimalkan laba yang diperoleh.Untuk mengalokasikan biaya-biaya tersebut secara akurat pada masingmasing produk yaitu dengan metode nilai jual relatif. Dimana data yang dipergunakan merupakan data primer yang didapat langsung dari perusahaan. Data yang digunakan berupa harga jual produk, biaya tenaga kerja langsung, biaya bahan baku, biaya operasional pabrik dan biaya pemasaran.Dari analisis yang dilakukan melalui perhitungan alokasi biaya bersama dengan menggunakan metode dengan nilai jual relatif tersebut dapat diketahui bahwa hasil yang diperoleh dari perhitungan alokasi biaya bersama pada Shmily Cupcake dengan menggunakan metode nilai jual relatif maka diperoleh alokasi biaya bersama untuk Nutella Cheese Cupcake sebesar Rp 56.723 dan untuk Cookies Cupcake sebesar Rp. 60.108 dari total biaya bersama sebesar Rp116.716, yang diperoleh dari biaya bahan baku, biaya tenaga kerja langsung dan biaya overhead pabri
\end{abstract}

\section{ABSTRACT}

Guidance of in the company needs to improve its business processes so that the appropriate production produced products can compete in the market . One such effort is to utilize one or several main raw material to produce two or more types of products are almost the same but with different variations to accurately allocate costs to each product so as to maximize profits. To allocate these costs accurately on each product is the relative sales value method. Where the data used is primary data obtained directly from the company. The data used in the form of selling price, direct labor costs, raw material costs, plant operating costs and marketing costs.From the analysis conducted through joint cost allocation calculation using the relative sales value method can be seen that the results obtained from the calculation of the cost allocation with the Cupcake Shmily using the relative sales value method of cost allocation obtained with Nutella Cheese Cupcake for Rp 56723 and Cookies Cupcake for Rp. 60108 of the total cost of Rp116.716 shared, derived from raw material costs, direct labor costs and factory overhead costs. 


\section{Latar Belakang}

\section{PENDAHULUAN}

Biaya bersama dapat dialokasikan kepada tiap-tiap produk bersama dengan menggunakan empat metode yang terdiri dari metode nilai jual relatif, metode kuantitatif, metode biaya perunit rata-rata dan metode rata-rata tertimbang. Dimana yang dibahas dalam pembahasan ini adalah metode nilai jual relatif yang banyak digunakan untuk mengalokasikan biaya bersama kepada produk bersama Nutella Cheese Cupcake dan Cookies Cupcake. Dasar pikiran metode ini adalah bahwa harga jual suatu produk merupakan perwujudan biaya yang dikeluarkan dalam memperoleh produk tersebut.

Tujuan alokasi biaya bersama adalah untuk perhitungan laba, agar dapat diketahui berapa kontribusi masing-masing produk bersama terhadap seluruh laba yang diperoleh perusahaan. Berdasarkan latar belakang masalah tersebut maka penulis dalam penulisan ini mengambil judul "ANALISIS ALOKASI BIAYA BERSAMA UNTUK PENENTUAN BIAYA PRODUKSI NUTELLA CHEESE CUPCAKE DAN COOKIES CUPCAKE PADA SHMILY CUPCAKES".

\section{Rumusan Masalah}

Dalam penulisan ini penulis mengambil perumusan masalah:

1. Bagaimanakah menganalisa alokasi biaya bersama untuk penentuan biaya produksi Nutella Cheese Cupcake dan Cookies Cupcake?

2. Apakah hasil analisa alokasi biaya bersama untuk penentuan biaya produksi Nutella Cheese Cupcake dan Cookies Cupcake?

\section{Tujuan penelitian}

Tujuan penulisan ini adalah:

1. Untuk mengetahui analisa alokasi biaya bersama untuk penentuan biaya produksi Nutella Cheese Cupcake dan Cookies Cupcake

2. Untuk mengetahui hasil analisa alokasi biaya bersama untuk penentuan biaya produksi Nutella Cheese Cupcake dan Cookies Cupcake

\section{Manfaat Penelitian}

Adapun manfaat yang diperoleh dari penelitian ini adalah:

a. Manfaat Akademis Memberikan nilai tambah bagi penulis berkaitan dengan judul atau tema yang diambil serta sebagai bagian dari syarat untuk mencapai gelar Setara Sarjana Muda.

b. Manfaat praktis bagi perusahaan yang menjadi objek penelitian, diharapkan hasil penelitian dapat menjadi acuan serta pertimbangan khusus dalam pengambilan keputusan dimasa akan datang.

\section{TINJAUAN PUSTAKA}

\section{Akuntansi Produk Bersama}

Masalah akuntansi dalam produk bersama adalah masalah alokasi biaya bersama. Alokasi tersebut bertujuan untuk penetuan harga pokok dan penentuan nilai persediaan. Dengan kata lain tujuan akhir alokasi biaya bersama adalah untuk memberikan informasi kepada manajemen baik untuk kepentingan penyusunan laporan keuangan. 
Akuntansi adalah seni penctatan, penggolongan, peringkasan dan pelaporan transaksi-transaksi keuangan suatu organisasi dengan cara-cara tertentu yang sistematis, serta penafsiran terhadap hasilnya.

Akuntansi biaya adalah salah satu dari sekian banyak displin ilmu dalam akuntans. Akuntansi biaya secara sederhana dapat diartikan dari istilahnya sebagai akuntansi yang khusus digunakan untuk pengukuran dan pelaporan biaya.

Dari definisi akuntansi biaya tersebut diatas, dapat diuraikan beberapa pengertian dalam akuntansi biaya, sebagai berikut.

1. Akuntansi biaya merupakan ILMU, dalam pengertian bahwa akuntansi biaya merupakan hal yang dapat dipelajari dan tentu saja telah memenuhi kaidah-kaidah tertentu untuk dapat diakui sebagai suatu displin ilmu, antara lain logis, dan telah diterima serta dipraktekkan oleh banyak orang.

2. Akuntansi biaya merupakan SENI, dalam pengertian bahwa akuntansi biaya adalah bagian disiplin ilmu social yang karakteristiknya antara lain didasarkan atas suatu set asumsi tertentu. Asumsi tretentu dapat diungkapkan baik secara implicit maupun eksplisit. Dan perhitungan dalam akuntansi biaya sebenarnya merupakan model yang merupakan abstraksi dari dunia nyata, yang yentu saja memliki berbagai keterbatasan tergantung pada set asumsi yang membentuk model itu sendiri.

\section{Pengertian Biaya bersama}

Biaya bersama adalah biaya mengoperasikan suatu fasilitas, aktivitas, atau objek biayayang dibagi oleh dua atau lebih pengguna. Tujuannya adalah untuk mengalokasikan biaya bersama ke setiap pengguna dengan cara yang wajar berdasarkan biaya individual dari objek biaya.

Biaya bersama adalah biaya yang timbul karena pemrosesan atau pabrikasi beberapa jenis barang secara bersama-sama (Armanto Witjaksono, 2006; 90).

Biaya bersama dikeluarkan untuk mengolah bahan baku menjadi berbagai macam produk yang berupa produk bersama mocca taart dan lemon taart. Pengertian biaya bersama menurut Mulyadi dalam bukunya akuntansi biaya, biaya bersama adalah biaya yang dikeluarkan sejak saat mula-mula bahan baku diolah sampai dengan saat berbagai macam produk dapat dipisahkan identitasnya.

Sedangkan menurut Abdul Halim dalam bukunya dasar-dasar akuntansi biaya 2 , biaya bersama adalah biaya yang dikeluarkan untuk memproduksi produk menjadi beberapa macam.

Dan menurut Supriyono dalam bukunya akuntansi biaya , biaya bersama adalah biaya produksi yang terdiri atas biaya bahan baku, biaya tenaga kerja langsung, dan biaya overhead pabrik yang semuanya tidak dapat diikuti jejaknya pada macam produk tertentu.

Dari pengertian diatas dapat ditarik kesimpulan biaya bersama adalah biaya yang dikeluarkan untuk mengolah bahan baku, tenaga kerja dan overhead pabrik yang menghasilkan dua jenis produk atau lebih.

\section{Pengertian Produk Bersama}

Bila dalam satu proses produksi dihasilkan lebih dari satu produk maka produk tersebut dinamakan produk bersama. Produk bersama adalah dua produk atau lebih yang diproduksi secara serentak dengan serangkaian proses atau dengan proses gabungan (Mulyadi, 2005; 335). 
Sedangkan menurut Abdul Halim dalam bukunya dasar-dasar akuntansi biaya, produk bersama adalah beberapa produk yang dihasilkan dari suatu rangkaian atau seri proses produksi secara serempak dengan menggunakan bahan baku, tenaga kerja dan overhead pabrik yang sama, yang tidak dapat dilacak, dibedakan atau dipisahkan pada setiap produk dan mempunyai nilai jual atau kuantitas produk relatif sama.

Dan menurut Supriyono dalam bukunya akuntansi biaya, produk bersama adalah beberapa macam produk yang dihasilkan bersama-sama dengan mengunakan satu macam atau beberapa macam bahan baku, tenaga kerja dan fasilitas pabrik yang sama tersebut tidak dapat diikuti jejaknya pada setiap macam produk tertentu.

Dari pengertian diatas dapat ditarik kesimpulan produk bersama adalah dua jenis produk atau lebih yang diproduksi secara bersama-sama dalam satu rangkaian proses produksi dan masing-masing produk mempunyai harga jual yang relatif sama.

\section{Jenis dan Sumber Data}

\section{METODE PENELITIAN}

Menurut Kuncoro (2001) data berdasarkan jenis terbagi dua, yaitu sebagai berikut.

1 Data kuantitatif, yaitu data yang dinyatakan dalam bentuk numerik seperti data laporan keuangan, data arus kas dan lain sebagainya.

2 Data kualitatif, yaitu data yang tidak dinyatakan dalam bentuk numerik tetapi berupa gambaran deskriptif dalam bentuk uraian seperti gambaran umum perusahaan, kegiatan operasional perusahaan dan data kepustakaan.

Dalam penelitian ini, penulis menggunakan analisis deskriptif yaitu menganalisis alokasi biaya bersama dengan cara mendeskripsikannya pada data data yang sudah ada.

Pada umumnya penelitian deskriptif merupakan penelitian non hipotesis sehingga dalam langkah penelitiannya tidak perlu merumuskan hipotesa. Penelitian yang diharuskan untuk menggunakan hipotesis adalah penelitian experimental, correlational dan explanatory. (Sugiyono, 2006:70)

Sumber data yang digunakan dalam sebuah penelitian adalah sebagai berikut:

1. Data sekunder merupakan sumber data penelitian yang diperoleh peneliti secara tidak langsung melalui media perantara (diperoleh dan dicatat oleh pihak lain). Data sekunder umumnya berupa bukti, catatan, atau laporan yang telah tersimpan dalam arsip yang dipublikasikan dan yang tidak dipublikasikan.

\section{Metode Pengumpulan Data}

Untuk mendapatkan data-data yang dibutuhkan dalam penulisan ini, maka penulis menggunakan metode penelitian lapangan dan kepustakaan.

\section{Metode penelitian lapangan (Field Research)}

Metode pengumpulan data melalui penelitian lapangan dilakukan dengan cara :

a. Wawancara yaitu teknik tanya jawab untuk mencari informasi dari sumber yang bersangkutan, dalam hal ini 
melakukan wawancara dengan piahak-pihak yang berkepentingan dengan masalah yang akan diteliti.

b. Pengamatan langsung yaitu teknik pengumpulan data yang dilakukan dengan cara terjun kelapang dan kemudian mengumpulkan data hasil pengamatanuntuk mendapatkan data yang lebih akurat.

\section{Metode penelitian kepustakaan (Library Research)}

Yaitu penelitian menggunakan data sekunder yang bersumber dari bukubuku yang erat kaitannya dengan masalah ini. Dimana dilakukan dengan mencari berbagai materi dari buku-buku yang dapat dijadikan acuan dalam penulisan ini.

\section{HASIL PENELITIAN DAN PEMBAHASAN Gambaran Umum Obyek Penelitian}

Pada umumnya setiap perusahaan menghendaki tujuan dari perusahaan yang telah ditetapkan bisa tercapai. Agar tujuan perusahaan tersebut dapat tercapai, maka perusahaan memerlukan struktur organisasi. Tujuan disusunnya suatu struktur organisasi yang jelas pada suatu perusahaan akan dapat memudahkan para karyawan dalam perusahaan tersebut untuk menjalankan pekerjaannya sesuai dengan tugas yang telah ditetapkan pada struktur organisasi yang telah disusun oleh perusahaan, sehingga tidak terjadi tumpang tindih dalam menjalankan pekerjaan masing-masing.

Struktur Organisasi perusahaaan sangat berguna untuk menentukan pembagian tiap-tiap departemen atau bagian, sehingga masing-masing karyawan dapat mengetahui tugas, tanggung jawab dan wewenang secara jelas.Adapun struktur organisasi pada perusahaan Shimily Cupcakes sangat sederhana karena perusahaan masih merupakan perusaan yang berbasis usaha dagang.

\section{Hasil Penelitian dan Pembahasan}

Berikut ini akan diuraikan toal penjualan Shimily Cupcakes selama bulan Oktober beserta rincian biaya produksi dan akan dijelaskan perhitungan alokasi biaya bersama pada Nutella Cheese Cupcake dan Cookies Cupcake.

\section{- Total Unit Produksi}

Dalam satu bulan Shimily Cupcakes memproduksi 15 jenis cupcakes.Berikut ini diuraikan total unit produksi masing-masing produk yang dijual oleh Shimily Cupcakes dalam satu bulan: 
Tabel 4.1

Total Unit Produksi Bulan Oktober 2013

\begin{tabular}{|c|c|}
\hline NAMA PRODUK & Total Unit Penjualan \\
\hline Nutella Milo & 750 \\
\hline Nutella Triple Chocolate & 750 \\
\hline Nutella Triple Cheese & 750 \\
\hline Nutella Cheese Cupcake & 750 \\
Cookies Cupcake & $\mathbf{7 5 0}$ \\
& 1.500 \\
\hline Red Velvet & 500 \\
\hline Red Velvet Oreo & 500 \\
\hline Nutella Almond & 750 \\
\hline Ferrero Rocher & 750 \\
\hline Oreo Cheese Cake & 500 \\
\hline Silverqueen & 500 \\
\hline Kindar Burno & 500 \\
\hline Snickars & 500 \\
\hline Cheese Vanila & 750 \\
\hline Chocolate m\&m & 500 \\
\hline Total Produksi & 9.500 \\
\hline
\end{tabular}

Sumber : Shimily Cupcakes

Jumlah unit produk

$$
\begin{aligned}
\text { Presentase Produk } & =\frac{}{\text { Jumlah keseluruhan unit produk }} \times 100 \% \\
\text { Presentase cupcakes } & =\frac{1.500}{9.500} \times 100 \%=\underline{15,8 \%}
\end{aligned}
$$

Jadi, presentase cupcakes sebesar $15,8 \%$ dari total produksi 9.500 unit produk yang dihasilkan Shimily Cupcakes dalam satu bulan. Presentase diperlukan agar memudahkan dalam perhitungan biaya tenaga kerja dan overhead pabrik yang diserap oleh masing-masing produk.

1. Perhitungan Pengalokasian Biaya Bersama Nutella Cheese Cupcake dan Cookies Cupcake

2. Proses Produksi Bersama

Shimily Cupcakes memproduksi Nutella Cheese Cupcake dan Cookies Cupcake melalui proses produksi gabungan dengan biaya produksi gabungan sebesar Rp. . 116.716 dari proses produksi gabungan tersebut menghasilkan dua (2) macam jenis produk yaitu Nutella Cheese Cupcake sebanyak 25 unit danCookies Cupcake sebanyak 25 unit. Berikut ini akan dijelaskan proses produksi Cheese Cupcake dan Cookies Cupcake untuk mengetahui titik pisah (split-off point) dan akan diuraikan data biaya produksi yang dikeluarkan Shimily Cupcakes untuk memproduksi Cheese Cupcake dan Cookies Cupcake. 
Biaya gabungan yang terjadi adalah dalam proses produksi nutella cheese cupcake dan cookies cupcake adalah pada proses produksi gabungan berupa pembuatan adonan cupcakes.. Pada proses produksi gabungan tersebut terdapat biaya yang dikeluarkan, biaya tersebut adalah biaya produksi gabungan atau biaya produksi bersama. Setelah itu adonan dipisahkan untuk dibentuk menjadi nutella cheese cupcake dan cookies cupcake. Titik inilah merupakan titik pisah (split-off point). Produk yang dihasilkan tidak dapat dijual pada saat titik pisah, maka perlu diproses lebih lanjut agar poduk menjadi barang jadi yang siap dipasarkan.Terdapat biaya-biaya yang dikeluarkan dalam pemrosesan lebih lanjut, tetapi biaya-biaya tersebut bukan biaya bersama sehingga dapat dibebankan ke masing-masing produk yang diproduksi.

\section{Biaya Produksi Bersama}

Biaya produksi gabungan yang dikeluarkan dalam memproduksi nutella cheese cupcake dan cookies cupcake terdiri dari biaya bahan baku, tenaga kerja dan overhead pabrik.

a. Biaya Bahan Baku (BBB)

Biaya bahan baku yang akan diuraikan berikut ini adalah merupakan biaya bahan baku bersama atau gabungan dalam satu kali produksi adonan 50 unit cupcakes.

Tabel 4.2

Biaya Bahan Baku Bersama (satu kali produksi)

\begin{tabular}{|l|l|l|l|}
\hline \multicolumn{4}{|l|}{ nutella cheese cupcake dan cookies cupcake } \\
\hline Bahan & Kuantitas & Harga per satuan & Jumlah \\
\hline Tepung terigu & 800 gram & 16 gram & Rp. 12.800 \\
\hline Telur & 10 butir & $1650 /$ butir & Rp. 16.500 \\
\hline Mentega tawar & 800 gram & 16 gram & Rp. 12.800 \\
\hline Gula pasir & 800 gram & 16 gram & Rp. 12.800 \\
\hline Coklat bubuk & 250 gram & 5 gram & Rp. 1.250 \\
\hline TOTAL & Rp. 56.150 \\
\hline
\end{tabular}

Jadi untuk memperoduksi 50 unit cupcakes mengeluarkan biaya bahan baku gabungan sebesar Rp. 56.150

b. Biaya Tenaga Kerja (BTK)

Shimily Cupcakes memperkerjakan 5 orang dengan uraian gaji bulanan sebagai berikut:

Tabel 4.3

Biaya Tenaga Kerja Bulanan

\begin{tabular}{|l|l|l|l|}
\hline Pekerjaan & Jumlah pekerja & $\begin{array}{l}\text { Jumlah Upah per } \\
\text { orang (Rp) }\end{array}$ & $\begin{array}{l}\text { Total Upah } \\
(\mathrm{Rp})\end{array}$ \\
\hline Manajer & 1 & 2.000 .000 & 2.000 .000 \\
\hline Chef Koki & 1 & 1.500 .000 & 1.500 .000 \\
\hline Administrasi & 1 & 1.000 .000 & 1.000 .000 \\
\hline Penjualan & 1 & 1.000 .000 & 1.000 .000 \\
\hline Kasir & 1 & 1.000 .000 & 1.000 .000 \\
\hline Total & 5orang & & Rp. 6.500 .000 \\
\hline
\end{tabular}

Sumber : Shimily Cupcakes, 2013 
Berikut ini perhitungan biaya tenaga kerja yang dikeluarkan dalam memproduksi Cupcakes.

Biaya Tenaga Kerja $=$ Total upah X Presentase Kue susen

Biaya Tenaga Kerja $=$ Rp 6.500.000 X15,8\%

$$
\begin{aligned}
& =\text { Rp.1.027.000/bulan } \\
& =\operatorname{Rp~34.233/hari~}
\end{aligned}
$$

Jadi biaya tenaga kerja yang dikeluarkan dalam memperoduksi nutella cheese cupcake dan cookies cupcake dalah sebesar Rp 1.027.000/bulan atau Rp 34.233/hari. Berikut ini rincian upah masing-masing pekerja untuk memperoduksi cupcakes.

Tabel 4.4

Biaya Tenaga Kerja Bulanan Untuk Cupcakes

\begin{tabular}{|l|l|l|}
\hline Pekerjaan & Jumlah Pekerja & Total upah (Rp) \\
\hline Manajer & 1 & Rp. 316.000 \\
\hline Chef koki & 1 & Rp. 237.000 \\
\hline Administrasi & 1 & Rp.158.000 \\
\hline Penjualan & 1 & Rp.158.000 \\
\hline Kasir & 1 & Rp.158.000 \\
\hline Total & 5orang & Rp. 1.027 .000 \\
\hline
\end{tabular}

Total Upah Pekerja Bulanan

Total Upah Pekerja $=\frac{}{\text { Presentase Biaya Tenaga Kerja }}$

c. Biaya Overhead Pabrik (BOP)

Biaya overhead pabrik terbagi atas BOP variable dan BOP tetap. Pada Shmily Cupcake yang termasuk dalam biaya overhead pabrik variable adalah biaya listrik dan biaya pemakaian bahan bakar gas.dan biaya telepon. Sedangkan untuk biaya overhead pabrik tetap adalah, biaya sewa bangunan, biaya depresiasi mixer, biaya depresiasi oven, biaya depsresiasi mesin kasir, biaya depresiasi mesin pendingin roti, dan biaya depresiasi rak display.

d. Biaya Variabel

Berikut ini merupakan uraian sekaligus perhitungan biaya overhead pabrik variable dan tetap yang dikeluarkan setiap bulan dalam memproduksi produk utama cupcake.

Tabel 4.5

Biaya Variabel

\begin{tabular}{|l|l|l|l|}
\hline Overhead Pabrik & Kuantitas & $\begin{array}{l}\text { Harga per unit } \\
(\mathrm{Rp})\end{array}$ & Total harga (Rp) \\
\hline $\begin{array}{l}\text { Bahan bakar gas } \\
\text { per bulan }\end{array}$ & R tabung 15.000 & Rp. 60.000 \\
\hline Listrik per bulan & - & - & Rp. 250.000 \\
\hline Biaya telepon & & & Rp. 400.000 \\
\hline Total & & Rp. 710.000 \\
\hline
\end{tabular}


Berikut ini perhitungan biaya variabel yang dikeluarkan selama satu bulan dalam memperoduksi cupcake.

Biaya Variabel $=$ Total Biaya Variabel X Presentase Kue susen

Biaya Variabel $=$ Rp. 710.000X15,8\%

$=$ Rp. $112.180 /$ bulan

$=$ Rp.3.739/hari.

e. Biaya Tetap

Berikut ini merupakan uraian biaya tetap beserta perhitungan penyusutannya.

1. Biaya sewa bangunan setiap bulannya sebesar Rp 2.500 .000

2. Biaya depresiasi mixer:

Depresiasi mixer $=\frac{10.000 .000-1.000 .000}{4 \text { tahun }}=$ Rp. $2.250 .000 /$ tahun

Rp $2.250 .000 \div 12$ bulan $=187.500 /$ bulan

4. Biaya depresiasi oven:

$$
\begin{aligned}
& \text { Depresiasi oven }=\frac{25.000 .000-1.000 .000}{4 \text { tahun }}=\text { Rp. } 6.000 .000 / \text { tahun } \\
& R p .6 .000 .000 \div 12 \text { bulan }=500.000 / \text { bulan }
\end{aligned}
$$

5. Biaya depresiasi mesin kasir:

$$
\text { Depresiasi mesin kasir }=\frac{6.000 .000-1.500 .000}{2 \text { tahun }}=\text { Rp. 2.250.000/tahun }
$$

$R p 2.250 .000 \div 12$ bulan $=187.500 /$ bulan

6. Biaya depresiasi mesin pendinginn roti (Cooler):

$$
\text { Depresiasi cooler }=\frac{15.000 .000-2.000 .000}{4 \text { tahun }}=\text { Rp. 13.000.000/tahun }
$$

Rp 13.000.000 $\div 12$ bulan $=1.083 .333 /$ bulan

7. Biaya depresiasi rak display

$$
\begin{aligned}
& \text { Depresiasi rak display }=\frac{7.500 .000-1.000 .000}{2 \text { tahun }}=\text { Rp.6.500.000/tahun } \\
& R p 6.500 .000 \div 12 \text { bulan }=541.666 / \text { bulan } \\
& \text { Jadi jumlah biaya tetap yang dikeluarkan untuk membuat memproduksi } \\
& \text { semua jenis cupcake setiap bulan adalah sebagai berikut : }
\end{aligned}
$$


Table 4.6

Biaya Tetap

\begin{tabular}{|l|l|}
\hline Biaya tetap & Biaya tetap per bulan \\
\hline Biaya sewa bangunan & Rp. 2.500 .000 \\
\hline Biaya depresiasi mixer & Rp. 187.500 \\
\hline Biaya depresiasi oven & Rp. 500.000 \\
\hline Biaya depresiasi mesin kasir & Rp. 187.500 \\
\hline Biaya depresiasi mesin pendingin roti & Rp. 1.083 .333 \\
\hline Biaya depresiasi rak display & Rp. 541.666 \\
\hline Total & Rp.4.999.999 \\
\hline
\end{tabular}

Berikut ini perhitungan biaya tetap yang dikeluarkan selama satu bulan dalam memperoduksi susen:

$$
\begin{aligned}
\text { Biaya Tetap } & =\text { Total Biaya Tetap X Presentase Kue susen } \\
\text { Biaya Tetap } & =\operatorname{Rp} 4.999 .999 \times 15,8 \% \\
& =\operatorname{Rp} 789.999 / \text { bulan } \\
& =\operatorname{Rp} 26.333 / \text { hari }
\end{aligned}
$$

Jadi total biaya overhead oabrik yang dikeluarkan untuk memperoduksi cupcake adalah sebesar Rp 902.179/bulan atau Rp 30.072/hari yang diperoleh dari penjumlahan total biaya variable dan total biaya tetap.

Berikut ini uraian total overhead pabrik yang dikeluarkan dalam memperoduksi cupcake nutella cheese cupcake dan cookies cupcake dalam satu bulan.

Tabel 4.7

BOP Cupcake

\begin{tabular}{|l|l|l|}
\hline Keterangan & Biaya variable & Biaya tetap \\
\hline Biaya bahan bakar gas & Rp.37.920 & \\
\hline Biaya listrik & Rp. 39.500 & \\
\hline Biaya telepon & Rp. 63.200 & \\
\hline Biaya sewa bangunan & & Rp. 395.000 \\
\hline Biaya depresiasi mixer & & Rp. 29.625 \\
\hline Biaya depresiasi oven & & Rp. 79.000 \\
\hline $\begin{array}{l}\text { Biaya depresiasi masin } \\
\text { kasir depresiasi }\end{array}$ & & Rp. 29.625 \\
\hline $\begin{array}{l}\text { Biaya rak } \\
\text { pendingin roti }\end{array}$ & & Rp. 171.166 \\
\hline $\begin{array}{l}\text { Biaya depresiasi } \\
\text { display }\end{array}$ & Rp. 140.620 & Rp. 85.583 \\
\hline \multicolumn{2}{|l|}{} \\
\hline Total & Rp.930.619 789.999 \\
\hline
\end{tabular}

Total biaya produksi yang dikeluarkan untuk memperoduksi nutella cheese cupcake dan cookies cupcake dapat diuraikan dalam tabel berikut ini: 
Tabel 4.8

Biaya Produksi

\begin{tabular}{|l|l|}
\hline Biaya Produksi & Jumlah Biaya \\
\hline Biaya Bahan Baku (BBB) & Rp. 56.150 \\
\hline Biaya Tenaga Kerja (BTK) & Rp. 34.233 \\
\hline Biaya Overhead Pabrik (BOP) & Rp. 26.333 \\
\hline Total & Rp. 116.716 \\
\hline
\end{tabular}

Jadi, dalam proses produksi gabungan untuk menghasilkan nutella cheese cupcake dan cookies cupcake sebanyak 50 unit mengeluarkan biaya produksi gabungan atau biaya produksi bersama sebesar Rp. 116.716 .

\section{Biaya Pemrosesan Lebih Lanjut}

Pada saat titik pisah (split-off point), nutella cheese cupcake dan cookies cupcake masih merupakan bahan mentah yang belum siap untuk diual sehingga dibutuhkan proses produksi lebih lanjut agar produk mentah tersebut menjadi produk jadi yang siap untuk dipasarkan. Dalam proses produksi lebih lanjut terdapat aliran biaya yang dikeluarkan yang disebut biaya proses lebih lanjut. Biaya tersebut sudah dapat dibebankan kepada masing-masing produk nutella cheese cupcake dan cookies cupcake Biaya pemrosesan lebih lanjut pada nutella cheese cupcake dan cookies cupcake diuraikan dalam table berikut ini:

Tabel 4.9

Biaya Pemrosesan Setelah Titik Pisah

\begin{tabular}{|l|l|l|l|}
\hline Bahan & Kuantitas & Harga per satuan & Total harga \\
\hline $\begin{array}{l}\text { Nutella cheese } \\
\text { cupcake } \\
\text {-toping keju }\end{array}$ & 500 gram & $80 / \mathrm{gr}$ & $\underline{\mathrm{Rp} 40.000}$ \\
-total & Rp.40.000 \\
\hline $\begin{array}{l}\text { Cookies cupcake } \\
\text {-toping oreo }\end{array}$ & 274gram & $30 / \mathrm{gr}$ & $\underline{\text { Rp.8.220 }}$ \\
-total & $\begin{array}{l}\text { Total Biaya Proses } \\
\text { Lebih Lanjut }\end{array}$ & & Rp.8.220 \\
\hline
\end{tabular}

\section{Alokasi Biaya Gabungan}

Nutella cheese cupcake dan cookies cupcake diproduksi dengan melalui proses produksi bersama dengan total biaya produksi sebesar Rp48.220. Proses produksi bersama tersebut menghasilkan 25 unit nutella cheese cupcake dengan harga jual $\mathrm{Rp}$ 22.500/unit dan 25 unit cookies cupcake dengan harga jual $\mathrm{Rp}$ 22.500/unit. Untuk menghitung alokasi biaya bersama pada nutella cheese cupcake dan cookies cupcake menggunakan alokasi biaya bersama dengan metode harga pasar atau harga jual relatif. Metode ini digunakan karena harga jual dari masing-masing produk nutella cheese cupcake dan cookies cupcake mengikuti harga pasaran yang ada. 
Tabel berikut ini akan menguraikan pengalokasian biaya bersama pada produk bersama nutella cheese cupcake dan cookies cupcake:

Tabel 4.10

Alokasi Biaya Bersama - Metode Harga Pasar

\begin{tabular}{|c|c|c|c|c|c|c|c|c|}
\hline Produk & $\begin{array}{c}\text { Unit } \\
\text { yang } \\
\text { diproduksi }\end{array}$ & $\begin{array}{l}\text { Harga jual } \\
\text { per } \\
\text { unit setelah } \\
\text { titik pisah }\end{array}$ & $\begin{array}{l}\text { Total harga } \\
\text { jual setelah } \\
\text { titik pisah }\end{array}$ & $\begin{array}{c}\text { Biaya proses } \\
\text { setelah } \\
\text { titik pisah }\end{array}$ & $\begin{array}{c}\text { Harga } \\
\text { pasar } \\
\text { hipotesis }\end{array}$ & $\begin{array}{c}\text { Rasio } \\
\text { harga } \\
\text { hipotesis }\end{array}$ & $\begin{array}{c}\text { Alokasi } \\
\text { biaya } \\
\text { gabungan }\end{array}$ & $\begin{array}{c}\text { Harga } \\
\text { pokok } \\
\text { persediaan }\end{array}$ \\
\hline $\begin{array}{l}\text { Nutella } \\
\text { cheese cupcake }\end{array}$ & 25 & Rp 22.500 & $\operatorname{Rp} 562.500$ & Rp 40.000 & Rp 522.500 & $48,6 \%$ & $\operatorname{Rp} 56.723$ & $\operatorname{Rp} 96.723$ \\
\hline $\begin{array}{l}\text { Cookies } \\
\text { cupcake }\end{array}$ & 25 & $\operatorname{Rp} 22.500$ & $\operatorname{Rp} 562.500$ & Rp 8.220 & Rp 554.280 & $51,5 \%$ & Rp 60.108 & Rp 68.328 \\
\hline Total & 50 & Rp 45.000 & Rp 1.125.000 & Rp 48.220 & Rp 1.076.780 & $100 \%$ & Rp 116.716 & Rp 165.051 \\
\hline
\end{tabular}

Total Harga Jual Setelah Titik Pisah = Unit yang Diproduksi X Harga Jual Per Unit Setelah Titik Pisah

Harga Pasar Hipotesis = Total Harga Jual Setelah Titik Pisah - Biaya Proses Setelah Titik Pisah

Rasio Harga Hipotesis = Harga Pasar Hipotesis per Produk/Total Harga Pasar Hipotesis Semua Produk

Alokasi Biaya Gabungan = Harga Pasar Hipotesis X Total Biaya Produksi

Harga Pokok Persediaan $=$ Alokasi Biaya Gabungan + Biaya Proses Setelah Titik Pisah

Jadi, alokasi biaya gabungan pada nutella cheese cupcake sebesar Rp 56.732 dan cookies cupcake sebesar Rp 60.108 dari total biaya produksi sebesar Rp116.716. Dari alokasi biaya bersama tersebut maka dapat ditentukan harga pokok persediaan per unit sebagai berikut;

nutella cheese $\frac{\operatorname{Rp~} 96.723}{25 \text { unit }}=\operatorname{Rp~3.868/Unit~}$
cookies $=$

\section{Kesimpulan}

\section{PENUTUP}

Setelah mengadakan analisis dan evaluasi pada Shmily Cupcake, maka dapat ditarik kesimpulan sebagai berikut:

Analisis alokasi biaya bersama sebagai biaya produksi untuk 1 bulan, dengan perhitungan alokasi biaya bersama yang diperlukan perusahaan untuk memproduksi nutella cheese cupcake memproduksi 25 unit dengan harga jual Rp.22.500 sehingga diperoleh total harga jual sebesar Rp. 562.500,- sedangkan untuk cookies cupcake memproduksi 25 unit dengan harga jual 22.500 sehingga diperoleh total harga jual Rp. 562.500.

Dari hasil analisis alokasi biaya bersama untuk produk bersama pada Shmily Cupcake menggunakan metode nilai jual relatif . dalam metode ini biaya bersama dialokasikan menurut nilai harga jual dari masing-masing atau jenis produk. Untuk menghitung alokasi biaya bersama, maka akan diketahui untuk nutella cheese cupcake Rp. 56.150 dan cookies cupcake Rp. 60.108 dari total 
biaya bersama sebesar Rp.116.716, yang diperoleh dari biaya bahan baku, biaya tenaga kerja langsung dan biaya overhead pabrik.

Saran

Dari kesimpulan yang telah diutarakan penulis diatas, maka penulis memberikan saran dan semoga saran ini dapat digunakan bagi prusahaan dalam mengambil kebijaksanaan pada masa yang akan datang, yaitu:

a. Biaya bersama adalah biaya yang dikeluarkan untuk mengolah bahan baku menjadi berbagai macam produk yang dapat berupa produk bersama. Sedangkan untuk produk bersama adalah beberapa macam produk yang dihasilkan bersama-sama dengan menggunakan satu macam atau beberapa macam bahan baku, tenaga kerja dan fasilitas pabrik yang sama.

b. Metode yang digunakan penulis adalah metode alokasi biaya bersama. Alokasi tersebut bertujuan untuk penentuan harga pokok dan penentuan nilai-nilai persediaan. Perhitungan alokasi biaya bersama diperoleh dari total niali harga jual setiap produk dibagi dengan total nilai jual seluruh produk dikalikan dengan total biaya bersama. Metode ini hanya dipakai untuk dua produk dalam perusahaan ini.

c. Apabila perusahaan semakin berkembang, maka diperlukan pengawasan intern yang baik untuk menjamin dan memastikan harga jual setiap produk apakah sudah efektif dan efisien sesuai dengan porsi tersebut. Agar perusahaan dapat menarik konsumen yang lebih banyak lagi sebaiknya perusahaan menambah fasilitas pelayanan / promosi yang sekiranya menjadi daya tarik tersendiri bagi perusahaan dibanding perusahaan lain dan agar ketetapan yang dibuat perusahaan dapat dipasarkan keuntungannya oleh kedua belah pihak.

\section{DAFTAR PUSTAKA}

Horngren, 2008. Cost Accounting diterjemahkan oleh

Lestari, Akuntansi Biaya jilid 2. Edisi keduabelas. Penerbit Erlangga.

Horngren \& Horrison, 2007, Accounting diterjemhkan oleh

Gratia Akuntansi jilid 1. Edisi ketujuh. Penerbit Erlangga.

Iskandar, 2013. Metodologi penelitian pendidikan dan social. Cetakan kelima.

Penerbit Referensi. Jakarta

Kuncoro, Mudrajad, 2009. Metode Riset untuk Bisnis \& Ekonomi penerbit Erlangga

Rudi Winanda 2011,

Alokasi Biaya bersama untuk Penentuan Harga Pokok Produksi

Libby, et al, 2008. Financial Accounting Diterjemahkan oleh Seputro. Akuntansi Keuangan. Edisi kelima. Penerbit Andi, Yogyakarta.

Mardiasmo, 2012, Akuntansi Keuangan Dasar 1. Cetakan ketiga. Edisi ketiga penerbit BPFE, Yogyakarta.

Mursyidi, 2010. Akuntansi Biaya, Cetakan Kedua. Penerbit Relika Aditama, Bandung.

Dadi Kuswandi, 2003, Alokasi Biaya Bersama Untuk Penentuan Harga Pokok

Produksi pada PT. Gucimas Santana Garment. gunadarma_20200169ssm_fe common cost.pdf-Adobe Reader. 
Reeves, et al, 2012, principles of Accounting, Diterjemahkan oleh Damayanti Dian,

Pengantar Akuntansi Buku 1. Penerbit Salemba Empat, Jakarta.

Salman, Kautsar 2013. Akuntansi Biaya. Cetakan Pertama, Penerbit Akademia, Jakarta.

Surnani 2012, Analisis Alokasi Biaya Bersama Untuk Produk Bersama Sate kambin

dan Tongseng Kambing pada UD. Pak Bardan. Penerbit Graha Sugiyono, 2010, Metode Penelitian Bisnis. Cetakan Ke-15, Penerbit Alfabeta Bandung.

Susatyo Herlambang, 2013, Pengantar Manajemen, Cetakan Pertama. Penerbit Gosyen Publishing, Yogyakarta.

Wahjono, Sentot, 2010, Perilaku Organisasi, Cetakan Pertama, Edisi Pertama, Penerbit Graha Ilmu, Yogyakarta.

Widilestariningtyas, dkk, 2012, Akuntasi Biaya, Cetakan Pertama, Penerbit Graha

Ilmu, Yogyakarta.

Wijaksono, Armanto, 2006, Akuntansi Biaya, Cetakan Pertama, Graha Ilmu, Yogyakarta. 